\title{
The unexpected rise of cohabitation in the Philippines: evidence of socioeconomic disadvantage or a second demographic transition?
}

Article

Accepted Version

Kuang, B., Perelli-Harris, B. and Padmadas, S. (2019) The unexpected rise of cohabitation in the Philippines: evidence of socioeconomic disadvantage or a second demographic transition? Asian Population Studies, 15 (1). pp. 8-27. ISSN 1744-1749 doi:

https://doi.org/10.1080/17441730.2018.1560664 Available at https://centaur.reading.ac.uk/76389/

It is advisable to refer to the publisher's version if you intend to cite from the work. See Guidance on citing.

To link to this article DOI: http://dx.doi.org/10.1080/17441730.2018.1560664

Publisher: Taylor and Francis

All outputs in CentAUR are protected by Intellectual Property Rights law, including copyright law. Copyright and IPR is retained by the creators or other copyright holders. Terms and conditions for use of this material are defined in the End User Agreement. 


\section{www.reading.ac.uk/centaur}

\section{CentAUR}

Central Archive at the University of Reading

Reading's research outputs online 


\section{The unexpected rise of cohabitation in the Philippines: \\ Evidence of socioeconomic disadvantage or a Second Demographic Transition?}

\section{Bernice Kuang, ${ }^{\text {a* }}$ Brienna Perelli-Harris ${ }^{\mathrm{b}}$ and Sabu S. Padmadas ${ }^{\mathrm{c}}$}

${ }^{a}$ Department of Social Statistics and Demography, Faculty of Social, Human and Mathematical Sciences, University of Southampton, Southampton, United Kingdom;

${ }^{b}$ Department of Social Statistics and Demography, ESRC Centre for Population Change, Faculty of Social, Human and Mathematical Sciences, University of Southampton, Southampton, United Kingdom

${ }^{c}$ Department of Social Statistics and Demography, Centre for Global Health, Population, Poverty and Policy, Faculty of Social, Human and Mathematical Sciences, University of Southampton, Southampton, United Kingdom

*Bernice Kuang, Department of Social Statistics \& Demography, Faculty of Social, Human \& Mathematical Sciences, University of Southampton, Highfield Campus, Southampton, SO17 1BJ, United Kingdom

Email: Bk2g14@soton.ac.uk

The authors gratefully acknowledge Dr. Midea Kabamalan from the Population Institute of the University of the Philippines for her constructive comments on earlier versions of this paper. We thank the UK Economic and Social Research Council for funding this research project. 


\title{
The unexpected rise of cohabitation in the Philippines: Evidence of socioeconomic disadvantage or a Second Demographic Transition?
}

\author{
ABSTRACT \\ Cohabitation has increased rapidly in the Philippines, quadrupling in prevalence from $6 \%$ \\ in 1993 to $24 \%$ in 2013 among young adult women. This increase is dramatic and \\ exceptional given the slow change in other family behaviours, such as low divorce rates \\ and continued high fertility, and the persistent influence of the Catholic Church. While \\ cohabitation is often framed as evidence of ideational change and liberalization, its \\ continued uptake over time may be associated with socioeconomic conditions. Using the \\ 2013 National Demographic and Health Surveys, we apply a discrete-time competing risks \\ model to examine the relationship between socioeconomic status and cohabitation, using \\ education as proxy for resources and opportunities available to women. Our findings \\ demonstrate that lower levels of education are significantly associated with a higher risk of \\ cohabitation, which suggests rising cohabitation in the Philippines is more linked to \\ socioeconomic disadvantage than the devaluing of marriage among educated elites.
}

Keywords: Cohabitation, Marriage, Education, Second Demographic Transition, Philippines, Demographic and Health Surveys

\section{Introduction}

Although cohabitation has been increasing in countries around the world, its meaning and role in family formation vary cross-nationally and by population subgroups (Esteve, Lesthaeghe, \& Lopez-Gay, 2012; Jampaklay \& Haseen, 2011; Perelli-Harris et al., 2014; Raymo, Iwasawa, \& Bumpass, 2009; Yu \& Xie, 2015). Cohabitation may be evidence of ideational change and liberalization, a shift referred to as a 'Second Demographic Transition' (SDT) (Lesthaeghe \& van de Kaa, 1986). From this perspective, ideational change diffuses through higher or prolonged education among elites who are the forerunners of value change and pioneers of new family behaviours. Alternatively, understanding changing family behaviours also depends on 
local and historical context (Heuveline \& Timberlake, 2004; Perelli-Harris et al., 2014). As cohabitation becomes more accepted, its continued uptake over time may be associated with socioeconomic conditions. Individuals of different socioeconomic backgrounds may have reasons for choosing cohabitation which reflect the values, norms, or constraints of their social strata. Depending on the population subgroup, cohabitation could represent individuals' increasingly liberal values or could be coping strategies related to economic disadvantage and instability (McLanahan, 2004; Perelli-Harris et al., 2010).

Compared with Europe and the Americas, cohabitation is atypical in Asia. However, the emergence of low fertility and postponement of marriage and childbearing in some Asian countries have prompted scholars to speculate the possibility of the SDT spreading to Asia (Atoh, Kandiah, \& Ivanov, 2004; Ghosh, 2016; Jones, 2007; Lesthaeghe, 2010; Yu \& Xie, 2015). Our research examines the unique case of the Philippines, where cohabitation has increased dramatically but other family behaviours relevant to the SDT, such as below replacement fertility or large-scale postponement of marriage and childbearing, have not occurred. The Philippines is also the only country in the world where divorce is illegal and the only option to legally dissolve a marriage is annulment ("The Family Code of the Philippines," 1987; Laranas, 2016). And while the SDT links modern contraception with the relaxation of sexual mores that lead to new relationship behaviours, modern contraceptive use in the Philippines remains relatively low, family planning services are inaccessible for young unmarried women, and abortion is illegal. Widespread international and internal migration has also led to the emergence of transnational families and mobile populations, introducing another layer of complexity. Furthermore, the Philippines, as one of the only Roman Catholic countries 
in Southeast Asia, has a strong colonial legacy, as well as complex cultural, political, and economic contexts.

To our knowledge, there is no systematic exploration of the large-scale shift towards cohabitation in the Philippines. Existing studies of cohabitation in the Philippines focus on youth and young adults and their attitudes to partnership (Kabamalan, 2004; Williams, Ogena, \& Kabamalan, 2007; Xenos \& Kabamalan, 2007). However, cohabitation in the Philippines has grown rapidly and markedly beyond a youth phenomenon, calling for a systematic exploration of the socioeconomic correlates of cohabitation across all age groups. Using the 2013 Philippines Demographic and Health Survey data, we investigate whether women who cohabit without marrying differ systematically from women who marry, focusing on individual level education as the main proximate indicator of socioeconomic status. Although education is an imperfect proxy, it represents the expectations and opportunities of different social strata in the Philippines and is closely linked to likelihood of poverty (PSA, 2016). This study provides insight into why and among whom cohabitation has increased in an underexplored country, generating new evidence of cohabitation trends in a non-Western context.

\section{Background}

\section{Cohabitation and socioeconomic status}

The SDT addresses the increasing importance of post-materialist 'higher order needs,' individualism, secularization, and gender equity, positing that new family behaviours, such as cohabitation, feature among populations that embody these characteristics. SDT behaviours are first adopted by elite, highly educated subgroups better positioned to negotiate higher order needs and challenge existing norms. In Asian societies, better educated women have largely 
opted to postpone marriage and childbearing rather than adopt cohabitation, due to traditional family values (Chen \& Li, 2014; Jones \& Gubhaju, 2009; Jones, Hull, \& Mohamad, 2011; Raymo, Park, Xie, \& Yeung, 2015). Nonetheless, there is also evidence of correlation between liberal, individualist attitudes and postponement of parenthood, as seen in Japan, South Korea, and Singapore (Lesthaeghe, 2010). In China, cohabitation is more likely among affluent, educated individuals exposed to Western culture (Yu \& Xie, 2015) and in Thailand, cohabitation is more common among urban university students as well as those with more liberal attitudes towards sex (Jampaklay \& Haseen, 2011). Alternatively, cohabitation may also be the resort of less advantaged populations who lack resources or economic stability to marry (Raymo et al., 2009).

The relationship between socioeconomic advantage and cohabitation may also depend on how cohabitation compares with marriage. Where cohabitation plays a similar role in family formation as marriage, socioeconomic conditions may be associated with both types of union formation (Jalovaara, 2012; Thornton, Axinn, \& Xie, 2007). However, because marriage is often associated with an elaborate wedding celebration, homeownership, and the purchase of costly household items, being ready for marriage is often synonymous with achieving a level of affluence unattainable for the disadvantaged (Edin \& Kefalas, 2005; Esara, 2012). This suggests that socioeconomic status could have a stronger relationship to marriage than cohabitation (Xie, Raymo, Goyette, \& Thornton, 2003).

Pregnancy and childbearing are also important correlates of cohabitation that intersect closely with socioeconomic disadvantage (Edin \& Kefalas, 2005; Perelli-Harris \& Gerber, 2011; Raley, 2001; Raymo et al., 2009). Single women cohabiting instead of marrying in response to a nonmarital pregnancy may indicate liberalization and the convergence of cohabitation and 
marriage as family forms (Raley, 2001). Alternatively, births in cohabitation may be more common among less advantaged women who lack the resources and stability perceived as necessary to marry in response to pregnancy (Edin \& Kefalas, 2005). Moreover, where nonmarital fertility is more common among the less advantaged, the polarization of family formation patterns across socioeconomic status could further exacerbate inequality (McLanahan, 2004). Disentangling the interconnections between childbearing, union formation, and disadvantage may provide further insight into the socioeconomic underpinnings of cohabitation and marriage.

\section{Cohabitation and the Filipino context}

Cohabitation has been historically documented in the Philippines, particularly among lowincome people to avoid the legal fees and celebration costs of marriage (Kabamalan, 2004). Although cohabitation has been associated with socioeconomic instability, such as unemployment or low socioeconomic status, (Kabamalan, 2004; Williams et al., 2007; Xenos \& Kabamalan, 2007), existing studies have examined cohabitation with the view that it is solely a temporary arrangement for young people, focusing on a very narrow age group using descriptive methods or cross-sectional methods which do not account for the rate or timing of union formation or circumstances at the time of entry into union. Moreover, the percentage of women currently cohabiting has rapidly increased across all age groups (Figure 1), highlighting the importance of considering cohabiters of all ages. Higher prevalence of cohabitation indicates either the incidence or duration of cohabitation has increased, suggesting the evolution of cohabitation as an increasingly acceptable, longer term family arrangement.

— Figure 1 about here - 
Furthermore, the growth of nonmarital fertility among cohabiters (Casterline \& Kabamalan, 2010) calls for examination of how childbearing, disadvantage, and cohabitation are interrelated, which to date has not been considered. Rising nonmarital fertility has been attributed to increased premarital sex and low family planning use (ICF, 2014; Natividad, 2013; YAFS, 2014) and could also be linked to cohabitation. Although marriage may be the preferred context for childbearing, an unplanned pregnancy among couples may hasten entry into cohabitation instead of marriage, due to the higher commitment and economic expectations associated with marriage, and the limited options for legal marital dissolution. Single parenting is also stigmatized (Medina 2001), which may further prompt cohabitation, despite the fact that approximately 13 percent of first time mothers in the Philippines are single, more than quadruple the percentage in 1993 (ICF, 2014). Furthermore, 32 percent of ever-partnered mothers were pregnant before they entered their first partnerships and 7 percent had already given birth (ICF, 2014). Given the interrelationships between childbearing, socioeconomic status, and union formation, the rise of premarital sex and the prevalence of pre-union pregnancy call for closer examination of pregnancy and childbearing as risk factors for union formation, and whether they are more likely to be related to cohabitation or marriage.

\section{Methods and data}

\section{Data and outcome variable}

The 2013 DHS is a nationally representative sample of 16,155 women aged $15-49$, interviewed from a pool of 16,437 eligible women. The DHS collects data on fertility and family planning, including data on the timing of first union and current union status. However, it does not collect detailed union histories, such as higher order unions or timing of union transitions or 
dissolutions. All interviewed women have current union status data and most women (95 percent) who had ever been in union reported the month and year they entered their first union. For the remaining 5 percent of women ever in union, the DHS imputed values for the month and year of first union. Of 10,643 women who had ever been in union, 921 women reported having had more than one union - less than 6 percent of the whole sample. For these women, we made educated assumptions regarding the type of first union. For example, currently married women who reported multiple unions are likely to have cohabited for their first union, since divorce is illegal and annulments rare. We assumed currently cohabiting women who reported multiple unions married for their first union because cohabitation is often the union type for higher order relationships precisely because legally dissolving a prior marriage is very difficult (Abalos 2017). ${ }^{\text {i }}$ For 90 women ( 82 currently married and 8 current cohabiting) there was no information on higher order unions, and we assumed they had only one union. The possibility of recall or social desirability biases cannot be ruled out. For example, women with children may hesitate to report being single, and married women may recall the start date of their unions more accurately than their cohabiting counterparts.

\section{Analytic strategy}

Our study's primary interest was to investigate union formation at the national level to identify correlates of entry into cohabitation. We also explored whether women who cohabit differ systematically from women who marry across age groups, particularly by socioeconomic disadvantage.

However, the analysis was not straightforward, because the wording in the DHS questionnaire did not directly ask the type of first union, and type of first union can only be implied based on current union status. This creates a problem for distinguishing between direct 
marriage and a marriage preceded by pre-marital cohabitation, raising potential right and left censoring issues. Therefore, we used two different strategies to investigate cohabitation, each addressing the limitations of the other. First, we focused on entry into first order unions and applied survival analysis and competing risks hazard models. ${ }^{\text {ii }}$ This approach required us to compare first cohabiting unions that had not transitioned to marriage by the time of interview and first unions that directly or eventually transitioned to marriage. The benefit of this approach is that it produces risks of entrance into partnership and addresses the issue of right censoring which is problematic when younger adults have not had time to enter into a partnership enabling us to better understand new behaviours which are rapidly emerging among some young adults. In addition, the discrete-time method allows for key variables such as education, age, and calendar time to vary over the observation period.

In order to provide basic descriptive risks of union formation, for example the age profile of entrance into different types of unions, we first conducted survival analysis using STATA v 13.0 (StataCorp 2013) and STCOMPET (Coviello \& Boggess, 2004) to estimate the cumulative incidences of unions that were still cohabiting at interview and unions that transitioned to marriage before interview. The competing event of interest was cohabitation and those who did not enter either a marriage or cohabitation by the time of survey were censored.

We then used a discrete-time competing risks hazard model to examine the educational gradient associated with entry into union. The outcome variable had three categories: 1) women who entered cohabitation and did not marry by the time of interview (which we will refer to as 'cohabitation'; 2) women who entered a union that either directly or subsequently transitioned to marriage by the time of interview (which we will refer to as 'marriage'); and 3) women who had never been in union by the time of interview (which we will refer to as 'single'). The unit of 
analysis over the observation period was person-months. Respondents entered the risk set at the month of their $14^{\text {th }}$ birthday and exited upon entry into first union. Women who never entered any union by time of interview were censored. ${ }^{\text {iii }}$ We estimate the hazard of union formation in each person month using the following model:

$$
h_{i t}(m)=\frac{\exp \left(\sum_{j} x_{i j t} \beta_{j m}\right)}{\sum_{k=1}^{M} \exp \left(\sum_{j} x_{i j t} \beta_{j k}\right)}
$$

with $h_{i t}(m)$ representing the hazard of respondent $i$ experiencing an event $m$ in month $t$, and $j$ representing the value of respondent $i$ 's covariate at time $t$. This is equivalent to the number of unions of type $m$ formed in month $t$, divided by the number of never in union women at risk in the beginning of month $t$. In each person-month, there are three possible outcomes $(M=3)$ : single, marriage, or cohabitation. For each outcome type $m$, there is a separate coefficient $\beta_{j m}$ estimated for the $j$ different covariates. The value of $\beta_{j m}$ is pegged to 0 for the reference category of 'single,' meaning the hazard is pegged to $1(\exp (0))$. The exponentiated $\beta_{j m}$ coefficient approximates the change in relative risk of entering a union related to one unit increase or category change in the value of covariate $j$. For example, the exponentiated coefficient for the low education category is the change in the risk of entering a union between low educated and medium educated women (the reference category for the education variable), while controlling for other variables.

Our second approach was to apply a cross-sectional multinomial logistic model based on current partnership status data which does not account for right censoring. Unlike the previous analysis, it does not require assumptions about unions that transitioned from cohabitation to marriage or assumptions about women with higher order unions, and we are able to incorporate 
additional variables measured only at the time of interview. We modelled age groups separately and present results for each age group to account for life-course differences.

\section{Independent variables}

\section{Education}

Our main independent variable of interest was education, a proxy widely used in the Philippines for measuring socioeconomic status (PSA, 2016). In the competing risks model, we used a timevarying categorical variable to describe the respondents' level of education each person month. The time-varying education variable was based on respondents' reported total years of education with the assumption that all respondents were continuously enrolled and began schooling at age 6, when primary school in the Philippines begins. Respondents transitioned from low education (6 years or fewer), to medium education (7-10 years), to high education (over 10 years), depending on their completed years of education each person month. For the cross-sectional multinomial logistic model, the education variable was fixed and based on the highest level of education attended by the respondent at the time of interview.

In addition to the level of educational attainment, school enrolment may also be related to union formation, as student status may be perceived as incompatible with partnership. Being enrolled in school may particularly delay marriage, which is typically associated with more preparation and a larger outlay of resources than cohabitation (Thornton et al., 2007). To explore this, we considered school enrolment as a binary time-varying explanatory variable in the competing risks model. 


\section{Pregnancy and parenthood status}

We included pregnancy and parenthood status in the competing risks model because reproductive behaviour, union formation, and disadvantage are often interrelated (Jalovaara, 2012; Raley, 2001; Raymo et al., 2009) and early union formation may be related to disadvantage through early childbearing. Depending on norms and socioeconomic circumstances, premarital pregnancy or birth may lead to marriage or cohabitation (Raley, 2001; Raymo et al., 2009). Based on these considerations and the high prevalence of pre-union pregnancies and births in the Philippines, we constructed the pregnancy/parenthood predictor as a time-varying categorical variable with five possible values - nulliparous, pregnant, parent of a $\leq 1$ year old, parent of a 2-3 year old, and parent of a 4 year old or older. This categorical variable references women's first pregnancy or birth, or oldest child. We set pregnancy to begin 7 months before a woman's first live birth because women may not be aware of their pregnancies any earlier and thus, unlikely to base partnership decisions on pregnancy any earlier. We did not account for pregnancies that ended in miscarriage or abortion due to lack of data. ${ }^{i v}$ Both pregnancy and parent status were included as separate possible independent variable values to examine the different implications pregnancy and giving birth may have for union formation and whether the patterns differ for marriage compared to cohabitation. Parent status was disaggregated according to the age of the first child to investigate how the risk of union formation after birth changes over time. We did not include pregnancy and parenthood status as predictors in the cross sectional models because the vast majority of partnered women $(93 \%)$ had already had a child at the time of interview. 


\section{Period}

We included a variable for historical period in the competing risks model to reflect the rapid increase in cohabitation over the past several decades. The categorical period dummy consisted of three separate decades spanning 1978-2007, and one final category consisting of 2008-2013, with the earliest decade as the reference category. Birth cohort was also tested to examine changing behaviours across cohorts, yielding similar results. We also tested an interaction term between education and period to explore whether the relationship between socioeconomic status and union formation has changed over time but did not ultimately include it in the model due to lack of significant effect. Because the cross-sectional models focus solely on the time of interview, we did not include period in these models.

Age

The respondent's current age was included in the competing risks model as a time-varying control. Both age and age squared were included in the competing risks model to account for non-linear relationships between age and union formation. Age was not included in the crosssectional analysis because we fit separate models for 18-19 year olds and each subsequent 10 year age group. ${ }^{v}$ We selected 18-19 as the youngest age group of interest because women under 18 at the time of interview cannot be legally married.

\section{Household wealth}

Another proxy of socioeconomic status is household wealth. The DHS does not collect individual income data due to the challenges of ensuring comparability and accounting for nonmonetary wealth in developing countries. Instead, the DHS uses principle components analysis to calculate an index which places households on a continuous scale of wealth, based on basic 
measures such as dwelling characteristics (i.e plumbing quality, roof material) and household assets (i.e ownership of radio, television, car). This scale is then calibrated into wealth quintiles. The DHS household wealth index is a validated proxy to measure current socioeconomic status, and widely used in developing countries (Filmer \& Pritchett, 2001). Due to lack of historical data on household wealth, we examined household wealth in the cross-sectional models only.

\section{Household structure}

We also examined the relationship between household structure and union status in the crosssectional models, specifically whether women live with either their parents or grandparents at the time of interview. Women who are married or cohabiting but still living with their parents or grandparents at the time of interview may differ from those who have formed their own households in either economic or emotional independence. Living in the parental home may also indicate a temporary or interim arrangement, and could imply either parental approval or control of a woman's relationship. Furthermore, because wealth is measured at the household level, controlling for household structure is important since women who still live with their parents and grandparents may tend to be from wealthier households than women who have moved out on their own. ${ }^{\text {vi }}$

\section{Place of Residence}

Because the DHS does not collect residential history data, we used a fixed residence variable measured at the time of interview in the cross-sectional model only to control for differences between rural and urban residents. While on average, rural residents may be more likely to form unions than urban residents, urban residence may represent exposure to more liberal attitudes and Western culture. 


\section{Results}

We first present descriptive statistics of current cohabiters, currently married women, and never in union women at time of interview. We then present results from the competing risks model, followed by the cross-sectional model. The competing events in the first approach are entry into a cohabiting union that did not transition to marriage by time of interview ('cohabitation') and entry in a union which started with direct marriage or married by the time of interview ('marriage'). The second analytic approach presents results from a cross-sectional model, modelling the likelihood of outcomes 'currently cohabiting,' 'currently married,' and 'never in union' at the time of interview.

\section{Descriptive analysis}

Table 1 presents characteristics of women by current relationship status. A smaller proportion of currently cohabiting women were highly educated or in the wealthiest quintiles, compared with both currently married women and never in union women. At the time of survey, currently cohabiting women's mean age was 29 years, younger than currently married women (36), but older than never in union women (22).

Nearly a third of currently cohabiting women lived with parents or grandparents at the time of interview, compared with 15 percent of currently married women and 76 percent of never in union women, which may indicate less financial or emotional independence among cohabiters compared with married women. While most currently married women lived in rural areas, the majority of both currently cohabiting and never in union women lived in urban areas. Finally, the percentage of current cohabiters who reported being Catholic was nearly 10 points higher than among currently married women. 
— Table 1 about here -

\section{Approach 1. Competing risks model- time to first union}

Figure 2 illustrates the young age profile of union formation in the Philippines, displaying the cumulative proportions of those entering different types of unions from age 14 to 49 . The estimates show that by approximately age 24 , half of all women had entered their first union and by age 50, approximately 90 percent of respondents had entered into a union.

— Figure 2 about here -

Women had a higher risk of entering unions which started with direct marriage or married by the time of interview (henceforth 'marriage') than by entering into a cohabiting union that did not transition to marriage by time of interview (henceforth 'cohabitation'). Half of all first marriages in the risk set occurred by about age 22, indicating swift uptake of marriage, followed by more gradual growth. The cumulative incidence of cohabitation also rapidly increased from age 14-21, followed by more gradual growth, suggesting that cohabitation is not confined to teenagers and young women.

Table 2 reveals that more than half of first order cohabiting unions were over five years in duration. This is contrary to previous research framing cohabitation as solely a temporary prelude to marriage for young people, and also contrary to cohabitation in Western contexts, which is generally markedly shorter in duration, dissolving around two years (Heuveline \& Timberlake, 2004).

— Table 2 about here -

\section{Competing risks model - multinomial logistic regression}

All relative risk coefficients displayed in Table 3 represent the ratio between two relative risk 
terms each associated with a unit or category change in the associated parameter. For example, the risk terms in the extreme left column of Table 3 reflect a comparison of slope of the educational gradient for cohabitation relative to the slope of the educational gradient for remaining single. Because first unions in the Philippines are generally formed early in the lifecourse and the competing risks model depicts speed of entry into first union, patterns of cohabitation and marriage may reflect the correlates of early union formation in general, instead of cohabitation or marriage specifically. To address this, we also model entry into cohabitation relative to marriage, to directly compare the two different union types (rightmost column).

— Table 3 about here -

The coefficients demonstrate a significant, strong negative educational gradient of cohabitation. Low educated women had a 36 percent higher risk of cohabitation, compared to medium educated women, while highly educated women had a 44 percent lower risk of cohabitation compared to medium educated women. For women who married, the middle column of Table 3 indicates a flatter educational pattern, with low educated women at a 34 percent higher risk of marriage compared to medium educated women, and highly educated women at a 10 percent lower risk of marriage compared to medium educated women.

The rightmost column of Table 3 shows that the risk of cohabitation relative to marriage is 37 percent lower for highly educated women, compared to medium educated women while low educated women and medium educated women are at a similar risk of cohabitation relative to marriage. Although there is a negative educational gradient of entry into both cohabitation and marriage, the direct comparison of the two gradients in the rightmost column shows that the slope of the educational gradient of cohabitation is significantly more negative than that of marriage, when comparing highly educated women with medium educated women. These 
results shows that lower educated women are more likely to enter a union earlier, and also more likely to cohabit than marry.

Pregnancy and parenthood status were both strongly related to the relative risk of entry into cohabitation and entry into marriage. Pregnant women had 17 times higher a risk of cohabitation and 20 times higher a risk of marriage than nulliparous women. Parenthood also increased the risk of both cohabitation and marriage, when compared with nulliparous women, although this risk was negatively associated with the age of the first child. For example, the leftmost column of Table 3 indicates that parents of a child 0-1 years of age had 5 times higher a risk of cohabitation than nulliparous women, while parents of a $4+$ year old had 2.5 times higher a risk of cohabitation than nulliparous women. The middle column shows that parents of 0-1 year olds had 3.7 times higher a risk of marriage than nulliparous women while parents of children 4 years old or older had a similar risk of marriage as nulliparous women. The decreased relative risk of union formation for women with older children may be because women who do not partner soon after birth may need time to find a new partner. In contrast, pregnant women and women with younger children may be more likely to partner with the father of their child.

Although pregnancy and childbearing may prompt both types of union, comparing cohabitation relative to marriage shows that pregnancy is more strongly linked to marriage and having a child is more strongly linked to cohabitation. The rightmost column of Table 3 shows that compared to nulliparous women, pregnant women had a 15 percent lower risk of cohabitation, relative to marriage. However, women who had already given birth consistently had a higher risk of cohabitation relative to marriage.

We found a positive relationship between age and entry into both types of union. For each year increase in age, women had an approximately 33 percent increased risk of entry into 
cohabitation and a 57 percent increase in the risk of entry into marriage. Comparison of cohabitation relative to marriage showed that each year increase in age was associated with a 15 percent decrease in the risk of cohabitation relative to marriage, meaning older women were at a higher risk of union formation in general, but younger women had a higher risk of cohabitation relative to marriage. The significant quadratic age term for both types of union also indicates the non-linear age pattern of union formation, with lower risks at both the youngest and oldest age groups. Decade was also significantly associated with cohabitation with women at a higher risk of cohabitation in nearly each successive decade, compared to a declining risk of marriage.

\section{Approach 2. Cross-sectional model with current union status}

The competing risks model showed a negative socioeconomic gradient of cohabitation, but it could be critiqued as anticipatory analysis. Because the data do not specify the type of union when the couple moved in together, we cannot take into account transitions from cohabitation to marriage. This may result in bias if those who cohabited before marrying were more educated than cohabiters who did not marry by interview. For example, highly educated women may start their relationships with cohabitation, but if they are more likely to transition into marriage than their less educated cohabiting counterparts, the socioeconomic gradient of cohabitation would be negatively biased. Therefore, we examine the socioeconomic correlates of women 'currently cohabiting' at time of interview from a cross-sectional perspective across age groups, compared to the baseline group of women 'currently married.' If cohabiters who have not transitioned to marriage later in the life-course are less educated and less wealthy than women who marry, this further supports the claim that cohabitation is associated with disadvantage. 


\section{Cross-sectional multinomial logistic model of socioeconomic status and risk of current}

cohabitation

Table 4 illustrates a relationship between socioeconomic status and risk of cohabitation relative to marriage that appears to change over the life-course. Due to space limitations, we display only the risk of cohabitation relative to marriage and do not display results for the risk of 'never in union' relative to marriage, although single women were included in the model. Among 18-19 year old women, there were no significant socioeconomic patterns of being in cohabitation versus marriage at the time of interview, while for older age groups (aged 20 to 49), a negative socioeconomic gradient emerged and was generally steepest at the oldest age groups. Older, highly educated women had between 35 and 43 percent lower risk of being in cohabitation versus marriage when compared to their medium educated counterparts, whereas low and medium educated women had similar risks of being in cohabitation relative to marriage. There was a similar age pattern between household wealth and the risk of cohabitation relative to marriage. Among the 20-29, 30-39 and 40-49 year old age groups, the wealthiest women had respectively 28, 55 and 65 percent lower risk of cohabitation relative to marriage, when compared with middle income women. For women 30-39 and 40-49, those in the second wealthiest quintile were at a respectively 33 and 39 percent lower risk of cohabitation versus marriage than middle-income women.

— Table 4 about here -

To highlight the educational differences between cohabiters and married women across the life-course, Figures $3 \mathrm{a}$ and $3 \mathrm{~b}$ display the predicted probabilities of current cohabitation and current marriage by education and age group. At the youngest age groups (18-19 and 20-29), there was a negative educational gradient for both cohabitation and marriage, suggesting that 
being in any type of union early in the life-course may be related to disadvantage. However, at older age groups, the educational gradient of marriage reversed direction and became flatter or positive, while the educational gradient of cohabitation remained persistently negative, demonstrating that women who cohabit at older ages were less privileged compared to their married counterparts.

— Figure $3 \mathrm{a}$ and $3 \mathrm{~b}$ about here -

As a final check, we compared the socioeconomic characteristics of 'currently cohabiting' and 'currently married' women who partnered recently (3 months prior to survey), with the assumption that married women were likely to have directly married, given the short interval of time at risk for union transition. We found a similar pattern, with cohabiters less educated and poorer than married women and do not display results due to space limitation.

\section{Discussion}

The Philippines is undergoing a unique transition where cohabitation is increasingly practiced while other family behaviours remain conservative. Although past research suggests cohabitation is a short prelude to marriage for youth (Kabamalan \& Ogena, 2013; Williams et al., 2007), our results show that most first cohabiting unions were over five years in duration, indicating that cohabitation is more often a longer term arrangement. Some shorter term cohabiting relationships may convert to marriage, but it is important that there are women who do cohabit for the long term. Moreover, cohabitation is practiced across the life-course, with 10-15 percent of women in their 30s and 40s still cohabiting at the time of interview. Contrary to previous literature, both the duration and age profile of cohabitation suggests that cohabitation may be an entrenched and persistent living arrangement, as the SDT posits. Although some 
argue that cohabitation has led to a 'late marriage pattern' in the Philippines (Xenos \& Kabamalan, 2007) two things are important to note. One is that the bulk of first unions still happen at an early age, regardless of union type, and another is that childbearing occurs in both marriage and cohabitation, meaning later marriage does not necessarily entail delayed childbearing as in the SDT pattern.

Also contrary to the SDT pattern, our competing risks model shows a negative educational gradient of cohabitation, relative to marriage, suggesting that cohabitation and marriage are distinct and cohabitation more strongly selective of the less educated. The crosssectional approach confirms findings from the competing risks model and also demonstrates changing educational and wealth patterns of cohabitation across the life-course. While previous cross-sectional studies linked cohabitation and disadvantage among youth, our cross-sectional results find a stronger negative relationship between disadvantage and cohabitation, relative to marriage, at older age groups.

In the competing risks model, becoming pregnant or having a child were very strong predictors of union formation for both cohabiting and married women, although pregnancy had a stronger link to marriage, while being a parent was more linked to cohabitation. This may mean that the incentive to marry is strong when a woman becomes pregnant — perhaps to legitimate the birth - but if she chooses to go forward with the taboo of a nonmarital birth, the social pressure to marry may become less relevant and cohabitation may be preferred. Parents of younger children had a higher risk of union formation than those with older children, possibly because women were more likely to partner with the father of their child soon after the birth. Furthermore, parents had a higher risk of cohabitation versus marriage which appeared to further increase with the age of the child, perhaps because as more time elapsed between birth and 
subsequent union formation, the likelihood of cohabiting with a new partner increased, while the likelihood of marrying the child's father decreased. These partnership and childbearing dynamics would require further qualitative investigation to confirm.

The negative socioeconomic gradient of cohabitation and young age at union formation in the Philippines are not consistent with the SDT, which posits that cohabitation increases due to ideational change among the elite. Instead, the Philippines' pattern is more reminiscent of 'diverging destinies' or the 'pattern of disadvantage' noted in the United States and across Europe (McLanahan, 2004; Perelli-Harris et al., 2010). The 'pattern of disadvantage' posits that while women of all socioeconomic backgrounds may cohabit, less privileged women are the most likely to have a birth within cohabitation. In such a context, continued uptake of cohabitation and nonmarital fertility among the less privileged reproduces and exacerbates patterns of socioeconomic inequalities. Our findings suggest a similar pattern in the Philippines, where cohabitation is related to disadvantage and those who have nonmarital births are more likely to cohabit than marry, which could further polarize class patterns of partnership and family formation. However, it is important to note the different implications of disadvantage in developing and developed countries. A fifth of Filipinos live below the poverty line of approximately \$1.20 US per day and (PSA, 2015), putting into perspective the practical realities of disadvantage for millions of Filipinos.

Our findings also demonstrate a rapid overall rise in cohabitation, as well as a recent decline in marital unions. The significant uptake of cohabitation in the Philippines among less advantaged women challenges the notion that new family behaviours are pioneered by the elite before being adopted en masse by the less privileged. From the perspective of both the 'pattern of disadvantage' and 'diverging destinies,' less traditional family behaviours were first adopted 
and normalized by privileged communities before the class gradients reversed; the liberalization of attitudes then created space for people of all backgrounds to make a wider range of partnership decisions based on their own circumstances (McLanahan, 2004; Perelli-Harris et al., 2010). The development of cohabitation in the Philippines does not provide clear evidence of such an evolution and instead indicates an unusually rapid pattern of changes with a consistent socioeconomic pattern over time, suggesting cohabitation has been a marker of disadvantage from its onset, and that its growth may represent a combination of both liberalized attitudes and resource constraint among this group.

The Filipino pattern also has important parallels with the 'cohabitation boom' in Latin America, in that it has occurred within the context of persistently early union formation and childbearing. Like the Philippines, many Latin American countries have a colonial legacy and large Catholic populations. However, cohabitation in Latin America has followed a more polarized path over time, with the emergence of different typologies of cohabitation representing both disadvantage and modernization and within a lower fertility context in most countries (Covre-Sussai, Meuleman, Botterman, \& Matthijs, 2015; Esteve et al., 2012). More recently, the socioeconomic gradient of cohabitation and nonmarital childbearing has flattened in Latin America, as highly educated women increasingly cohabit and give birth in cohabitation (Laplante, Martin, \& Cortina, 2015). In contrast, the socioeconomic pattern of cohabitation does not appear to have changed over time in the Philippines, although it may change in the future if the growth of cohabitation among lower socioeconomic strata normalizes cohabitation politically and socially, paving the way for the elite to adopt cohabitation as a more accepted living arrangement. 
Finally, the policy climate in the Philippines, particularly the illegality of divorce and abortion, the limited availability of family planning, and the emphasis on co-residential nuclear families, is particularly conservative and may act simultaneously as both an impetus for cohabitation and also an obstacle to widespread ideational change in other family domains, preventing full convergence to SDT related values. Without access to legal divorce, cohabitation may be appealing to those who fear relationship instability, especially lower income populations who also cannot realistically access the resources required for a costly annulment procedure. Cohabitation allows flexibility and freedom to enter and change partnerships without the same legal implications, an option especially important for separated people who are unable to remarry. More recently, changes to family policies have extended the rights of children born to unwed parents (Republic Acts 9255 and 9858), which may have helped to normalize nonmarital cohabitation. Cohabitation may therefore also represent a reactionary measure to both the restrictive divorce law and the more liberalized family policies. Finally, the large-scale international migration of working age men and women undoubtedly has an impact on familial cohesiveness and perhaps also on attitudes toward partnership. Without many accessible avenues for dissolving marital unions, international labour migration among married Filipinos has sometimes been referred to as 'Filipino divorce' (Bennhold, 2011).

The lack of full union history data is a limitation of the present analysis and we cannot rule out recall or social desirability bias in self-reported partnership data. Further analysis of union formation dynamics and its correlates will require nationally representative data with indepth partnership histories, which to date, are not collected in the Philippines. Nonetheless, this research is a novel analysis of a large national level dataset in a highly populated but understudied country, providing key insight into the unexpected growth of cohabitation in the 
Philippines within the larger context of family formation patterns worldwide. Future research should investigate men and women's attitudes, ideals, and beliefs toward cohabitation and marriage, as well as the role of cohabitation in family formation, and how partnership decisions are related to childbearing behaviour. This would allow for a more in-depth understanding of the meaning of cohabitation in the Philippines and its growing importance as a family form.

\section{References}

Atoh, M., Kandiah, V., \& Ivanov, S. (2004). The Second Demographic Transition in Asia? Comparative Analysis of the Low Fertility Situation in East and South-East Asian Countries. The Japanese Journal of Population, 12(1), 42-75

Bennhold, K. (2011, March 7, 2011). From afar, moneymaker and mother, The New York Times.

Casterline, J. B., \& Kabamalan, M. M. M. (2010). The Growing Significance of Nonmarital Fertility in the Philippines. 11th National Convention on Statistics.

Chen, Y.-C. C., \& Li, J.-C. A. (2014). Family Change in East Asia In J. Treas, J. Scott \& M. Richards (Eds.), The Wiley Blackwell Companion to the Sociology of Families (Vol. 1, pp. 61-82): John Wiley \& Sons, Ltd.

Coviello, V., \& Boggess, M. (2004). Cumulative incidence estimation in the presence of competing risks. The Stata Journal, 4(2), 103-112

Covre-Sussai, M., Meuleman, B., Botterman, S., \& Matthijs, K. (2015). Traditional and Modern Cohabitation in Latin America: A Comparative Typology. Demographic Research, 32(32), 873-914

Edin, K., \& Kefalas, M. (2005). Promises I can keep: Why poor women put motherhood before marriage: University of California Press

Esara, P. (2012). Moral Scrutiny, Marriage Inequality: Cohabitation in Bangkok, Thailand. The Asia Pacific Journal of Anthropology, 13(3), 211-227

Esteve, A., Lesthaeghe, R., \& Lopez-Gay, A. (2012). The Latin American Cohabitation Boom, 1970-2007. Population and Development Review, 38(1), 55-81

The Family Code of the Philippines, Executive Number 209 Cong. Rec. (1987).

Filmer, D., \& Pritchett, L. H. (2001). Estimating wealth effects without expenditure data- or tears: An application to educational enrollments in states of India. Demography, 38(1), 115-132

Ghosh, S. (2016). Second Demographic Transition or Aspirations in Transition: An Exploratory Analysis of Lowest Low Fertility in Kolkata, India. Asian Population Studies. doi: 10.1080/17441730.2016.1203211

Heuveline, P., \& Timberlake, J. M. (2004). The Role of Cohabitation in Family Formation: The United States in Comparative Perspective Journal of Marriage and Family, 66, 1214-1230

ICF. (2014). Philippines National Demographic and Health Survey 2013. Manila, Philippines and Rockville, Maryland: ICF \& Philippines Statistics Authority.

Jalovaara, M. (2012). Socio-economic resources and first-union formation in Finland, cohorts born 196981. Population Studies, 66(1), 69-85 
Jampaklay, A., \& Haseen, F. (2011). Marital Unions and Unmarried Cohabitation in Bangkok, Thailand. Asian Population Studies, 7(2), 137-156

Jones, G. W. (2007). Delayed Marriage and Very Low Fertility in Pacific Asia Population and Development Review, 33(3), 453-478

Jones, G. W., \& Gubhaju, B. (2009). Factors Influencing Changes in Mean Age at First Marriage and Proportions Never Marrying in the Low-Fertility Countries of East and Southeast Asia. Asian Population Studies, 5(3), 237-265. doi: 10.1080/17441730903351487

Jones, G. W., Hull, T. H., \& Mohamad, M. (2011). Marriage Trends in Insular Southeast Asia: Their Economic and Socio-Cultural Dimension. In G. W. Jones, T. H. Hull \& M. Mohamad (Eds.), Changing Marriage Patterns in Southeast Asia. Abingdon, Oxon: Routledge.

Kabamalan, M. M. (2004). New Path to Marriage The Significance of Increasing Cohabitation in the Philippines. Philippines Population Review, 3(1), 112-129

Kabamalan, M. M., \& Ogena, N. B. (2013). Marriage as ideal cohabitation as practical: Revisiting meanings of marriage in the Philippines IUSSP XXVII International Population Conference. Busan, Korea.

Laplante, B., Martin, T. C., \& Cortina, C. (2015). Childbearing within marriage and consensual union in Latin America, 1980-2010. Population and Development Review, 41(1), 85-108

Laranas, G. d. M. (2016). Will the Philippines finally legalize divorce?, New York Times.

Lesthaeghe, R. (2010). The Unfolding Story of Second Demographic Transition Population and Development Review, 36(2), 211-251

Lesthaeghe, R., \& van de Kaa, D. J. (1986). Twee demografische transities ? In R. Lesthaeghe \& D. J. van de Kaa (Eds.), Bevolking: Groei en Krimp (pp. 9-24). Deventer: Van Loghum Slaterus.

McLanahan, S. (2004). Diverging Destinies: How Children Are Faring Under the Second Demographic Transition. Demography, 41(4), 607-627. doi: 10.1353/dem.2004.0033

Natividad, J. (2013). Teenage pregnancy in the Philippines: Trends, correlates and data sources. Journal of the ASEAN Federation of Endocrine Societies, 28(1), 30-37

Perelli-Harris, B., \& Gerber, T. (2011). Nonmarital childbearing in Russia: Second Demographic Transition or Pattern of Disadvantage? Demography, 48, 317-342

Perelli-Harris, B., Mynarska, M., Berrington, A., Berghammer, C., Evans, A., Isupova, O., ... Vignoli, D. (2014). Towards a new understanding of cohabitation: Insights from focus group research across Europe and Australia. Demographic Research, 31(34), 1043-1078

Perelli-Harris, B., Sigle-Rushton, W., Kreyenfeld, M., Lappegard, T., Keizer, R., \& Berghammer, C. (2010). The Educational Gradient of Childbearing Within Cohabitation in Europe. Population and Development Review, 36(4), 775-801

PSA. (2015). Poverty in the Philippines. Retrieved from https://psa.gov.ph

PSA. (2016). One in every ten Filipinos aged 6 to 24 years old is an out of school child and youth. Retrieved from https://psa.gov.ph

Raley, R. K. (2001). Increasing fertility in cohabiting unions: Evidence for the Second Demographic Transition in the United States? . Demography

38(1), 59-66

Raymo, J. M., Iwasawa, M., \& Bumpass, L. (2009). Cohabitation and Family Formation in Japan. Demography, 46(4), 785-803

Raymo, J. M., Park, H., Xie, Y., \& Yeung, W.-j. J. (2015). Marriage and Family in East Asia: Continuity and Change. Annual Review of Sociology, 41(1), 471-492. doi: 10.1146/annurev-soc-073014-112428

Thornton, A., Axinn, W. G., \& Xie, Y. (2007). Marriage and Cohabitation. Chicago: The University of Chicago Press

Williams, L., Ogena, N., \& Kabamalan, M. (2007). Cohabitation in the Philippines: Attitudes and Behaviors among Young Women and Men. Journal of Marriage and Family 69(5), 1244-1256 
Xenos, P., \& Kabamalan, M. M. M. (2007). Emerging Forms of Union Formation in the Philippines. Asian Population Studies, 3(3), 263-286. doi: 10.1080/17441730701746417

Xie, Y., Raymo, J. M., Goyette, K., \& Thornton, A. (2003). Economic potential and entry into marriage and cohabitation Demography 40(2), 351-367

YAFS. (2014). 2013 Young adult fertility and sexuality 4 key findings Quezon City: Demographic Research and Development Foundation Inc. (DRDF) and Univeristy of the Philippines Population Institute (UPPI).

Yu, J., \& Xie, Y. (2015). Cohabitation in China: trends and determinants. Population and Development Review, 41(4), 607-628 
Table 1. Socio demographic profile of respondents by union status at time of interview

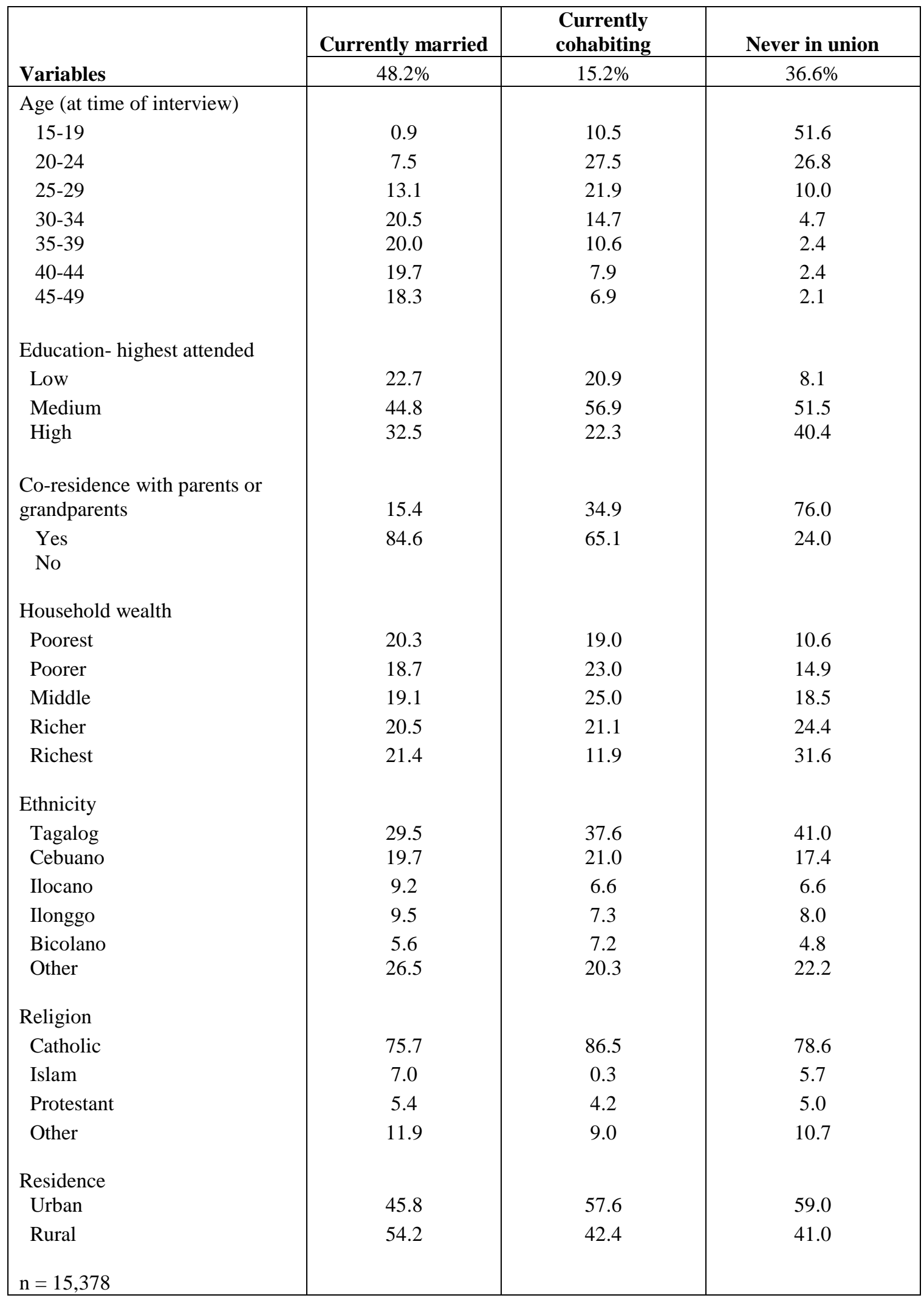

Note: the column percentages add to 100. Separated/divorced and widowed women are excluded (n=777) 
Table 2. Percent of first order unions in each 5 year duration increment, by union type

\begin{tabular}{|l|c|c|}
\hline \multirow{2}{*}{$\begin{array}{l}\text { Duration of union, in } \\
\text { years }\end{array}$} & \multicolumn{2}{|c|}{ \% of first order union } \\
\cline { 2 - 3 } & $\begin{array}{c}\text { Direct/ eventual marriage } \\
(\mathrm{n}=8,289)\end{array}$ & $\begin{array}{c}\text { Cohabiting } \\
(\mathrm{n}=2,354)\end{array}$ \\
\hline $0-4$ & 11.7 & 43.3 \\
$5-9$ & 19.9 & 25.4 \\
$10-14$ & 21.3 & 11.7 \\
$15-19$ & 17.9 & 7.7 \\
$20-24$ & 15.6 & 6.3 \\
$25-29$ & 11.0 & 4.2 \\
$30+$ & 2.6 & 1.4 \\
Total & 100.0 & 100.0 \\
\hline
\end{tabular}


Table 3. Results from competing risks model showing relative risk ratios (RRR) for entry into cohabitation versus single, marriage versus single, and cohabitation versus marriage, by background characteristics

\begin{tabular}{|c|c|c|c|c|c|c|}
\hline \multirow[b]{2}{*}{ Variables } & \multicolumn{2}{|c|}{ Cohabitation versus Single } & \multicolumn{2}{|c|}{ Marriage versus Single } & \multicolumn{2}{|c|}{ Cohabitation versus Marriage } \\
\hline & RRR & $(95 \% \mathrm{CI})$ & RRR & $(95 \% \mathrm{CI})$ & RRR & $(95 \% \mathrm{CI})$ \\
\hline $\begin{array}{l}\text { Pregnancy and parental status } \\
\text { Nulliparous (reference) } \\
\text { Pregnant } \\
\text { Parent of } 0-1 \text { year old } \\
\text { Parent of } 2-3 \text { year old } \\
\text { Parent of } 4+\text { year old }\end{array}$ & $\begin{array}{r}1.00 \\
17.48 \\
4.98 \\
2.70 \\
2.48\end{array}$ & $\begin{array}{l}(15.41-19.82)^{* * *} \\
(4.15-5.98)^{* * *} \\
(1.97-3.70)^{* * *} \\
(1.86-3.31)^{* * *}\end{array}$ & $\begin{array}{r}1.00 \\
20.46 \\
3.66 \\
1.37 \\
0.92\end{array}$ & $\begin{array}{l}(19.04-21.98)^{* * *} \\
(3.24-4.14)^{* * *} \\
(1.10-1.72)^{* *} \\
(0.73-1.15)\end{array}$ & $\begin{array}{l}1.00 \\
0.85 \\
1.36 \\
1.97 \\
2.70\end{array}$ & $\begin{array}{l}(0.75-0.98)^{*} \\
(1.10-1.69)^{* *} \\
(1.34-2.90)^{* * *} \\
(1.87-3.91)^{* * *}\end{array}$ \\
\hline $\begin{array}{l}\text { Current age } \\
\text { Current age squared }\end{array}$ & $\begin{array}{l}1.33 \\
0.99\end{array}$ & $\begin{array}{l}(1.23-1.44)^{* * *} \\
(0.99-1.00)^{* * *}\end{array}$ & $\begin{array}{l}1.57 \\
0.99\end{array}$ & $\begin{array}{l}(1.50-1.64)^{* * *} \\
(0.99-0.99)^{* * *}\end{array}$ & $\begin{array}{l}0.85 \\
1.00\end{array}$ & $\begin{array}{l}(0.78-0.92)^{* * *} \\
(1.00-1.00)^{*}\end{array}$ \\
\hline $\begin{array}{l}\text { Period } \\
1978-1987 \text { (reference) } \\
1988-1997 \\
1998-2007 \\
2008-2013\end{array}$ & $\begin{array}{c}1.00 \\
1.08 \\
2.47 \\
4.85\end{array}$ & $\begin{array}{l}(0.87-1.34) \\
(2.00-3.04)^{* * *} \\
(3.96-5.95)^{* * *}\end{array}$ & $\begin{array}{l}1.00 \\
0.89 \\
0.88 \\
0.44\end{array}$ & $\begin{array}{l}(0.82-0.96)^{* *} \\
(0.80-0.95)^{* *} \\
(0.40-0.48)^{* * *}\end{array}$ & $\begin{array}{r}1.00 \\
1.21 \\
2.81 \\
11.09\end{array}$ & $\begin{array}{l}(0.96-1.53) \\
(2.25-3.52)^{* * *} \\
(8.85-13.90)^{* * *}\end{array}$ \\
\hline Total number of person-months $=1,462,759$ & & & & & & \\
\hline
\end{tabular}

RRR: Relative Risk Ratios; ***Significant at the 0.001 level; ** significant at the 0.01 level; *significant at the 0.05 level 
Table 4. Results from cross-sectional multinomial logistic regression model showing relative risk ratios (RRR) of cohabitation at time of interview versus marriage at time of interview

\begin{tabular}{|c|c|c|c|c|c|c|c|c|}
\hline \multirow[b]{3}{*}{ Variables } & \multicolumn{8}{|c|}{ Currently cohabiting (baseline currently married) } \\
\hline & \multicolumn{2}{|r|}{$18-19$} & \multicolumn{2}{|c|}{$20-29$} & \multicolumn{2}{|c|}{$30-39$} & \multicolumn{2}{|r|}{$40-49$} \\
\hline & RRR & $(95 \% \mathrm{CI})$ & RRR & $(95 \% \mathrm{CI})$ & RRR & $(95 \% \mathrm{CI})$ & RRR & $(95 \% \mathrm{CI})$ \\
\hline \multicolumn{9}{|l|}{ Education level } \\
\hline Medium (reference) & 1.00 & & 1.00 & & 1.00 & & 1.00 & \\
\hline Low & 0.61 & $(0.30-1.23)$ & 0.98 & $(0.77-1.25)$ & 1.22 & $(0.93-1.59)$ & 0.89 & $(0.66-1.19)$ \\
\hline High & 1.45 & $(0.5-4.21)$ & 0.63 & $(0.51-0.77)^{* * *}$ & 0.65 & $(0.50-0.85)^{* *}$ & 0.57 & $(0.38-0.86)^{* *}$ \\
\hline Middle (reference) & 1.00 & & 1.00 & & 1.00 & & 1.00 & \\
\hline Poorest & 0.78 & $(0.30-2.00)$ & 0.72 & $(0.54-0.97) *$ & 0.75 & $(0.54-1.03)$ & 1.37 & $(0.93-2.02)$ \\
\hline Poorer & 0.88 & $(0.35-2.26)$ & 1.10 & $(0.86-1.41)$ & 0.95 & $(0.71-1.27)$ & 0.84 & $(0.58-1.23)$ \\
\hline Richer & 1.18 & $(0.31-4.50)$ & 1.04 & $(0.80-1.35)$ & 0.67 & $(0.51-0.89)^{* *}$ & 0.61 & $(0.41-0.91)^{*}$ \\
\hline Richest & 0.41 & $(0.11-1.64)$ & 0.71 & $(0.52-0.97)^{*}$ & 0.45 & $(0.32-0.62) * * *$ & 0.35 & $(0.22-0.56)^{* * *}$ \\
\hline \multicolumn{9}{|l|}{ Residence } \\
\hline Rural (reference) & 1.00 & & 1.00 & & 1.00 & & 1.00 & \\
\hline Urban & 1.34 & $(0.62-2.87)$ & 2.28 & $(1.86-2.80)^{* * *}$ & 1.95 & $(1.56-2.43) * * *$ & 2.54 & $(1.90-3.38)^{* * *}$ \\
\hline Constant & 2.34 & $(0.85-6.45)$ & 0.52 & $(0.40-0.67)^{* * *}$ & 0.19 & $(0.14-0.24)^{* * *}$ & 0.11 & $(0.08-0.15)^{* * *}$ \\
\hline Total Observations & & 1,144 & & 4,790 & & 3,951 & & 3,398 \\
\hline
\end{tabular}

RRR: Relative Risk Ratios; ***Significant at the 0.001 level; ** significant at the 0.01 level; *significant at the 0.05 level 


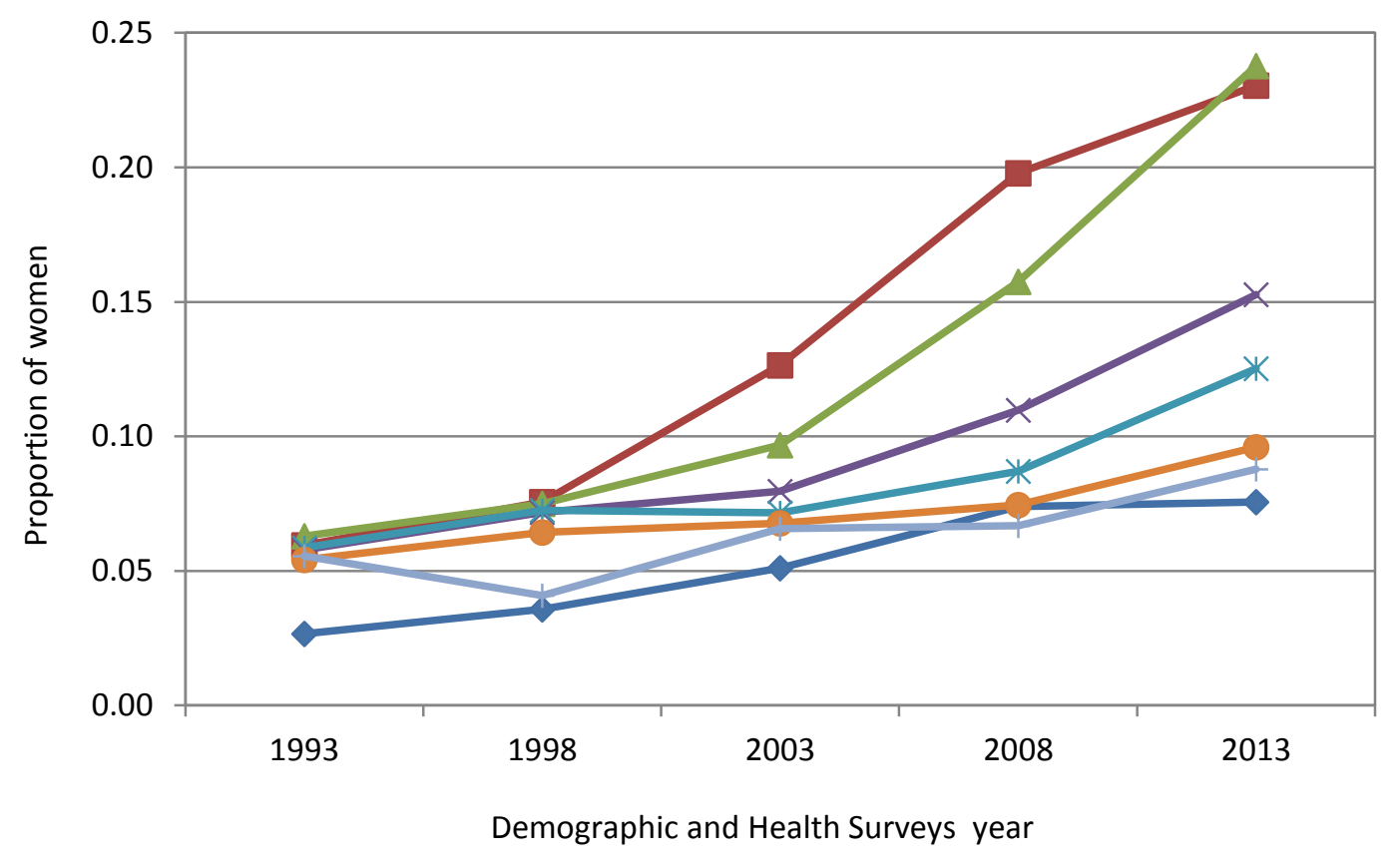

$\longrightarrow$ 15-19 $\longrightarrow$ 20-24 25-29 30-34 $\longleftarrow$ 35-39 40-49

Figure 1. Proportion of women cohabiting at time of interview in each age group, 1993-2013 


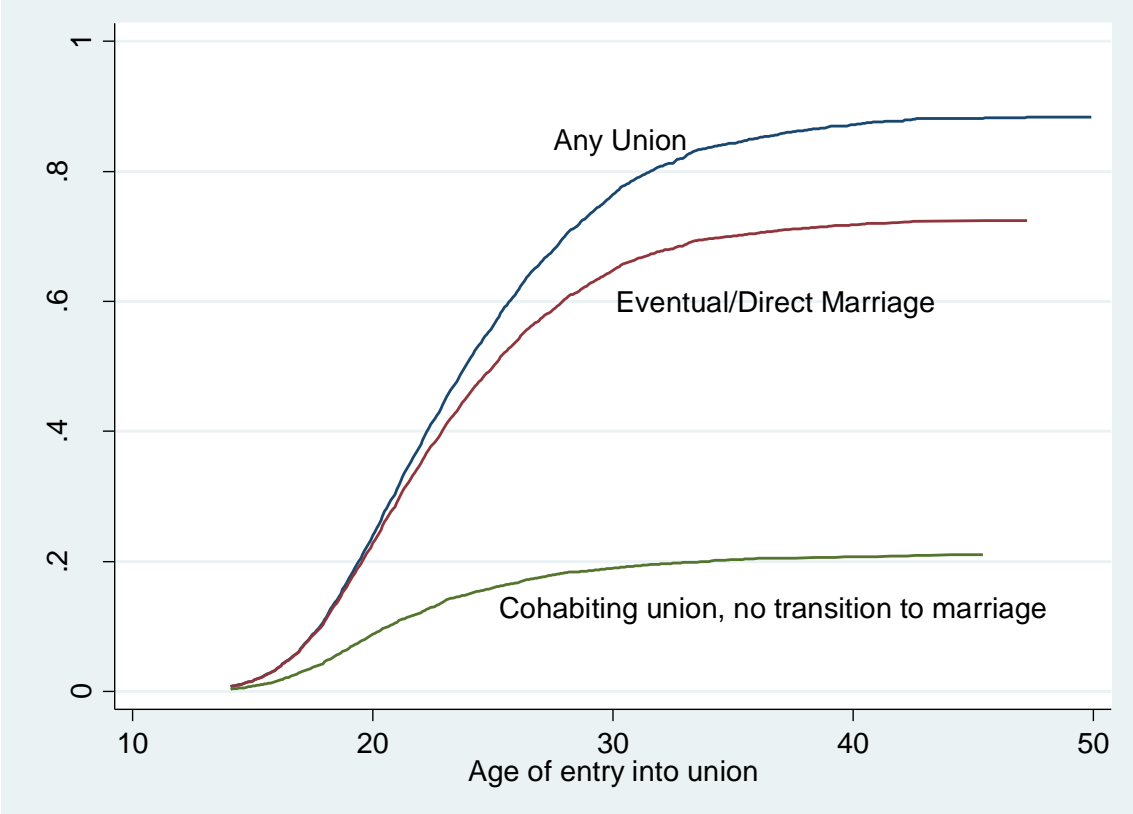

Figure 2. Cumulative probability of entry into first order cohabiting union, first order union with direct/eventual entry to marriage, or either type of union, by age 


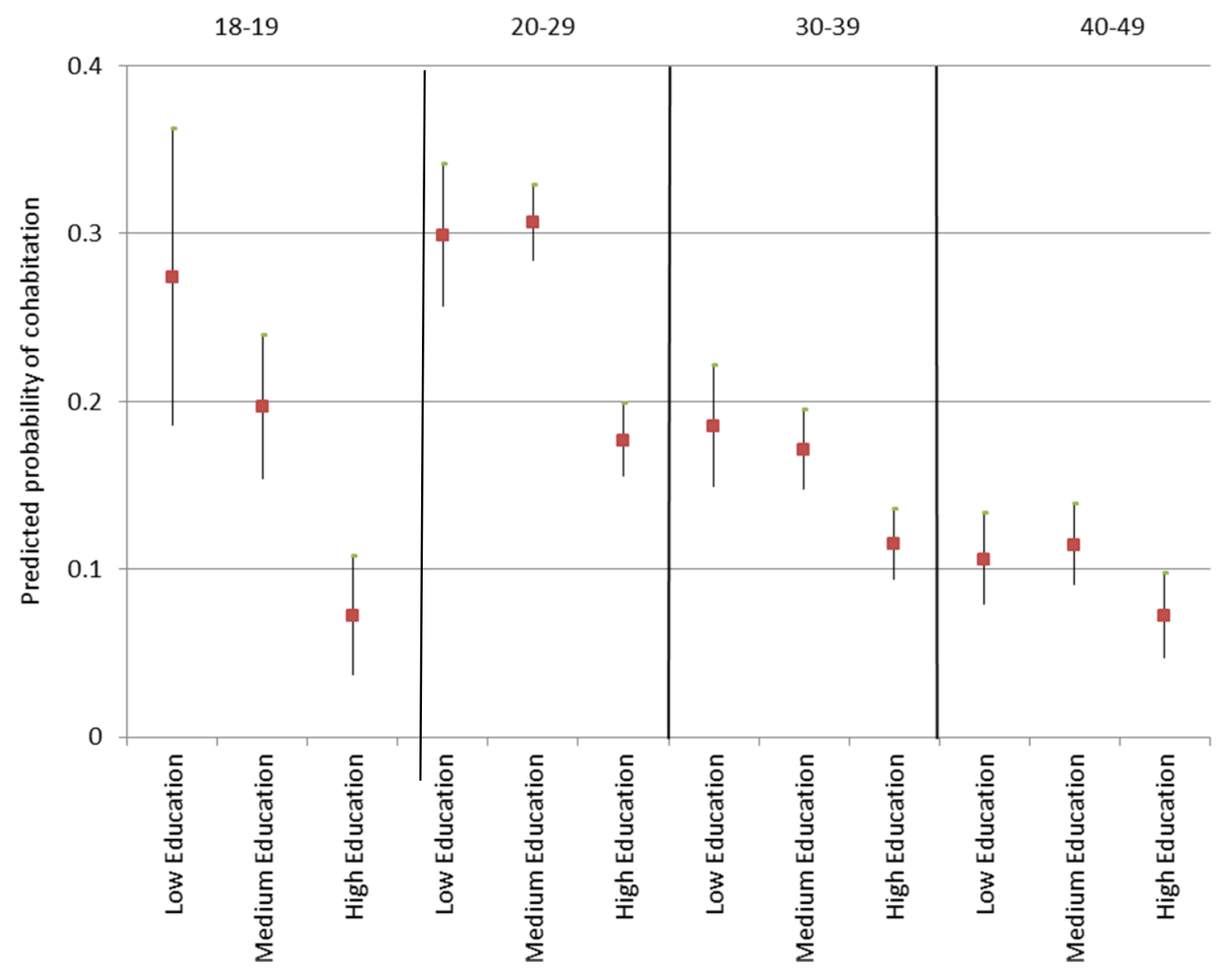

Figure 3a. Predicted probability of cohabitation from cross-sectional multinomial logistic regression model, by education level and age group 


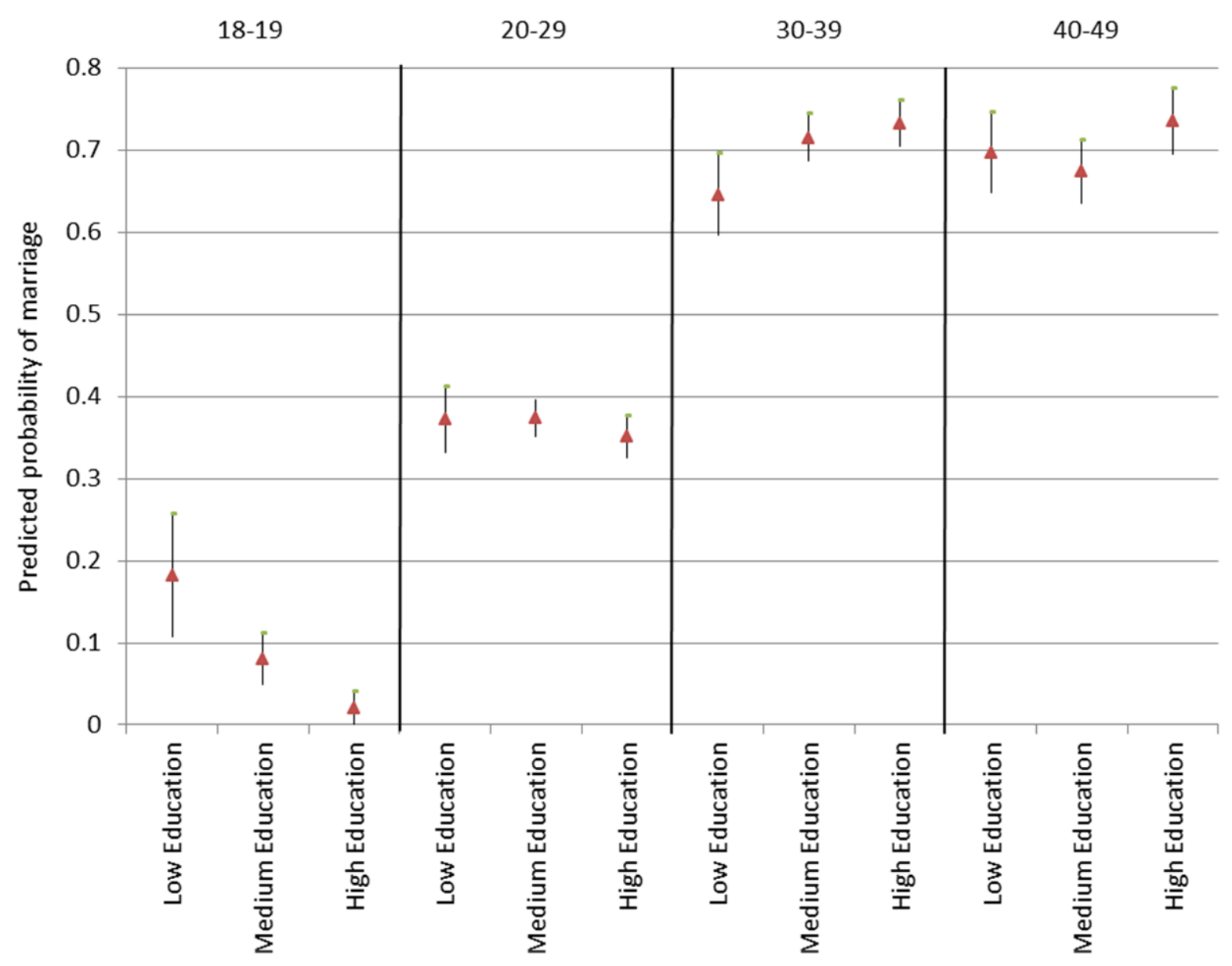

Figure 3b. Predicted probability of marriage from cross-sectional multinomial logistic regression model, by education level and age group

i Because assumptions were made about women who had experienced multiple unions, we conducted robustness checks to test these assumptions. We did this by running the competing risks model with outcome variables based on a variety of different assumptions regarding first union type for women who reported higher order unions and found that our main findings remained consistent.

ii This model requires that the IIA (Independence of Irrelevant Alternatives) is met. Visual comparison of coefficients between models did not suggest substantial differences. However, we conducted a test 
of seemingly unrelated estimation to see whether the IIA assumption could be rejected and based on the results, the assumption was rejected. As an additional check, we also ran the model adjusting for clustering at the household level and found no differences in the main educational patterns.

iii 173 subjects who reported entering a union before the month of their $14^{\text {th }}$ birthday were assumed to have failed in the month after they turned 14, at exact age 14 years and 1 month, thereby contributing one month of survival.

${ }^{\text {iv }}$ Because pregnancy may have a large effect size on union formation, we also ran the competing risk model without the pregnancy/parenthood variable for a sensitivity analysis. We found no effect on the main education patterns.

${ }^{\mathrm{v}}$ We also fit models for each five year age group for women 20-49 and found the main patterns were consistent.

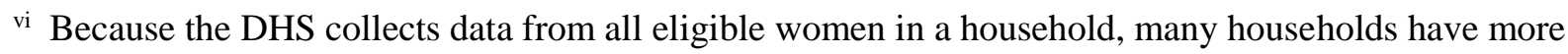
than one respondent. To investigate potential clustering issues, we ran both the competing risks model and the cross-sectional models while accounting for clustering at the household level. The results were very similar to the results of the main models so we ruled out household level clustering as a major issue. 